Article

\title{
Response Surface Methodology as a Useful Tool for Evaluation of the Recovery of the Fluoroquinolones from Plasma-The Study on Applicability of Box-Behnken Design, Central Composite Design and Doehlert Design
}

\author{
Andrzej Czyrski *(i) and Hubert Jarzębski \\ Chair and Department of Physical Pharmacy and Pharmacokinetics, Poznań University of Medical Sciences, \\ Święcickiego 6 Street, 60-781 Poznań, Poland; hubertjarz95@gmail.com \\ * Correspondence: aczyrski@ump.edu.pl; Tel.: +48-61-8546433
}

Received: 3 March 2020; Accepted: 11 April 2020; Published: 17 April 2020

\begin{abstract}
The aim of this study was to find the best design that is suitable for optimizing the recovery of the representatives of the 2nd, 3rd and 4th generation of fluoroquinolones. The following designs were applied: Central Composite Design, Box-Behnken Design and Doehlert Design. The recovery, which was a dependent variable, was estimated for liquid-liquid extraction. The time of shaking, $\mathrm{pH}$, and the volume of the extracting agent (dichloromethane) were the independent variables. All results underwent the statistical analysis (ANOVA), which indicated Central Composite Design as the best model for evaluation of the recovery. For each analyte, an equation was generated that enabled to estimate the theoretical value for the applied conditions. The graphs for these equations were provided by the Response Surface Methodology. The statistical analysis also estimated the most significant factors that have an impact on the liquid-liquid extraction, which occurred to be $\mathrm{pH}$ for ciprofloxacin and moxifloxacin and the volume of an extracting solvent for levofloxacin.
\end{abstract}

Keywords: fluoroquinolones; optimization; recovery; drug analysis

\section{Introduction}

Fluoroquinolones are the antibacterial agents that possess a wide bactericidal activity against Gram-positive (for example S. Pneumoniae) and Gram-negative (for example P. aeruginosa or B. Fragilis) bacteria [1,2]. They can be found in different matrices such as pharmaceutical formulations, biological samples (blood, serum, saliva) or food samples (meat). Different techniques of sample preconditioning such as liquid-liquid extraction, solid-phase extraction, microextraction, dilution, or protein precipitation can be applied. The applied technique depends on the matrix used [3]. Liquid-liquid extraction (LLE) is a very common technique of isolation. The analyte is extracted from a hydrophilic matrix with an organic solvent. The extraction procedure purifies the sample prior to injecting onto the chromatographic system [4]. LLE is more favorable than solid-phase extraction due to its simplicity-the sample is only shaken with an organic solvent. The factors that may influence the analyte's recovery are $\mathrm{pH}$, the volume of the extracting solvent, and time of extraction. According to FDA guidelines, the recovery should be consistent and reproducible but it does not have to reach the value of $100 \%$ [5]. The evaluation of the best conditions for recovery might be time-consuming. In the optimization, the response surface methodology (RSM) in which the surface can take the different shapes, is useful [6]. It is based on mathematical and statistical techniques. The response (dependent variable) is described quantitatively with the polynomial equation. The dependent variable 
is optimized when several factors are taken into consideration simultaneously. It can also be analyzed as one variable at a time. In this situation, only one parameter is optimized and the others should remain on the same level. It generates too much raw data and it might be impossible to interpret the optimal conditions properly. The application of chemometric design can overcome this problem. The number of experiments is limited and it is possible to estimate the mutual interactions between the independent variables $[7,8]$.

In the optimization process, it is necessary to apply a proper design. The data can be correlated linearly or by the quadratic models. The models that are desirable for the factorial analysis are Box-Behnken Design (BBD), Doehlert Design (DD) and Central Composite Design (CCD), which are classified as response surface designs. They are the symmetrical designs [9]. They make it possible to approximate the response function to experimental data with the quadratic functions. They are useful when the linear functions cannot be applied [8]. These three designs analyze the responses of the independent variables on different levels. In BBB, the experimental points are located on a hypersphere equidistant from the central point. The CCD has the following parts: the points of factorial design, the axial points, and the central point. In the DD, the intervals between the levels present a uniform distribution [8]. The abovementioned models can be found in the literature in optimizing the different extracting procedures such as LLE for 1.4-dihydropyridines [4], ultrasound-assisted extraction for colchicine [10], microextraction for psychoactive substances [11], microvave extraction of the essential oil [12], LLE of fluoroquinolones in food [13], LLE of gallic acid [14] or cloud point extraction in analysis of the metal's traces [15], stir bar sorptive extraction in the analysis of the volatile compounds in vinegar [16] or liquid-phase extraction of metamizole from biological samples and animal feed [17].

The aim of this work was to find the best design that might be useful in the analysis of the recovery of fluoroquinolones. This paper presents the statistical evaluation of the three factorial designs in the optimization of recovery. It indicates which design is suitable and evaluates the significant interactions between the independent variables.

\section{Materials and Methods}

\subsection{Reagents}

Levofloxacin (LEVO), Ciprofloxacin (CIPRO), sodium monophosphate and orthophosphoric acid were purchased by SigmaAldrich (Steiheim, Germany). Moxifloxacin (MOXI) was purchased by SantaCruz Biotechnology (Dallas, TX, USA). Acetonitrile (ACN), methanol (MeOH), triethylamine (TEA), and dichloromethane (DCM) were purchased by Merck (Darmstadt, Germany). All reagents were of HPLC grade. The plasma was obtained from the Local Blood Centre.

\subsection{The Design Matrices}

The following designs were analyzed: Box-Behnken Design, Doehlert Design, and Central Composite Design. In our study, we applied circumscribed CCD for which $|\alpha|=1.68$ for three factors [9]. They are listed in Tables 1-3. The values of each coded factor are presented in Table 4 . The method for codification of the values was described by Bezerra et al. [8]. 
Table 1. The Central Composite Design.

\begin{tabular}{ccc}
\hline Buffer $\mathbf{p H}$ & $\begin{array}{c}\text { Coded Factors } \\
\text { Volume of DCM }\end{array}$ & Time \\
\hline-1 & -1 & -1 \\
1 & -1 & -1 \\
-1 & 1 & -1 \\
1 & 1 & -1 \\
-1 & -1 & 1 \\
1 & -1 & 1 \\
-1 & 1 & 1 \\
1 & 1 & 1 \\
$-\alpha$ & 0 & 0 \\
$\alpha$ & 0 & 0 \\
0 & $-\alpha$ & 0 \\
0 & $\alpha$ & 0 \\
0 & 0 & $-\alpha$ \\
0 & 0 & $\alpha$ \\
0 & 0 & 0 \\
\hline
\end{tabular}

Table 2. The Doehlert Design.

\begin{tabular}{ccc}
\hline Buffer $\mathbf{p H}$ & $\begin{array}{c}\text { Coded Factors } \\
\text { Volume of DCM }\end{array}$ & Time \\
\hline 1 & 0 & 0 \\
0.5 & 0.866 & 0 \\
0.5 & 0.289 & 0.817 \\
-1 & 0 & 0 \\
-0.5 & -0.866 & 0 \\
-0.5 & -0.289 & -0.817 \\
0.5 & -0.866 & 0 \\
0.5 & -0.289 & -0.817 \\
-0.5 & 0.866 & 0 \\
0 & 0.577 & -0.817 \\
-0.5 & 0.289 & 0.817 \\
0 & -0.577 & 0.817 \\
0 & 0 & 0 \\
\hline
\end{tabular}

Table 3. The Box-Behnken Design.

\begin{tabular}{ccc}
\hline Buffer $\mathbf{p H}$ & $\begin{array}{c}\text { Coded Factors } \\
\text { Volume of DCM }\end{array}$ & Time \\
\hline-1 & -1 & 0 \\
1 & -1 & 0 \\
-1 & 1 & 0 \\
1 & 1 & 0 \\
-1 & 0 & -1 \\
1 & 0 & -1 \\
-1 & 0 & 1 \\
1 & 0 & 1 \\
0 & -1 & -1 \\
0 & 1 & -1 \\
0 & -1 & 1 \\
0 & 1 & 1 \\
0 & 0 & 0 \\
\hline
\end{tabular}


Table 4. The levels of the factors.

\begin{tabular}{cccc}
\hline The Coded Level & Buffer $\mathbf{p H}$ & Volume of DCM (mL) & Time (min) \\
\hline$-\alpha$ & 4.82 & 0.820 & 1.60 \\
-1 & 5.50 & 1.500 & 5.00 \\
-0.866 & - & 1.634 & - \\
-0.817 & - & - & 5.92 \\
-0.577 & - & 1.923 & - \\
-0.5 & 6.00 & - & - \\
-0.289 & - & 2.211 & - \\
0 & 6.50 & 2.500 & 10.00 \\
0.289 & - & 2.789 & - \\
0.5 & 7.00 & - & - \\
0.577 & - & 3.077 & - \\
0.817 & - & - & 14.08 \\
0.866 & - & 3.360 & - \\
1 & 7.50 & 3.500 & 15.00 \\
$\alpha$ & 8.18 & 4.180 & 18.40 \\
\hline
\end{tabular}

\subsection{The Optimization of the Extraction Procedure}

Two-hundred microliters of the human blank plasma was spiked with $25 \mu \mathrm{L}$ of the standard (CIPRO, LEVO or MOXI) stock solution, in which the concentration of the analyte was $100 \mathrm{mg} / \mathrm{L}$, and the $25 \mu \mathrm{L}$ of internal standard solution (LEVO for CIPRO and MOXI, CIPRO for LEVO determination) which concentration of the stock solution was $60 \mathrm{mg} / \mathrm{L}$. The goal concentration of the internal standard in the plasma sample was $6 \mathrm{mg} / \mathrm{L}$, and the analyte $10 \mathrm{mg} / \mathrm{L}$. Two-hundred-and-fifty microliters of the phosphate buffer $(50 \mathrm{mM})$ was added to the proper volume of DCM (VDCM) defined in Table 4 . The proper $\mathrm{pH}$ was shifted with a concentrated orthophosphoric acid. The mixture was shaken on a shaker. The organic layer was transferred to the tube and evaporated to dryness in the sample concentrator in $45^{\circ} \mathrm{C}$. The dry residue was dissolved in $200 \mu \mathrm{L}$ of the mobile phase and injected onto the chromatographic column. The VDCM, the $\mathrm{pH}$ of the buffer, and the time of the shaking were the independent variables. The recovery was the response in this study. According to Dejaegher et al. [9], the number of repeats in the central point was three. The samples, for which the recovery was tested for the optimized conditions, were done in five replicates for three concentrations of the analyte in plasma i.e., $2 \mathrm{mg} / \mathrm{L}, 6 \mathrm{mg} / \mathrm{L}$ and $8 \mathrm{mg} / \mathrm{L}$.

\subsection{Statistical Analysis}

The statistical analysis was done by Design Expert ver. 11, Statistica ver. 13.1 and MiniTab ver. 18. The ANOVA test was applied. The results are presented in Table 5. The $p<0.05$ was considered as statistically significant.

The $\mathrm{R}^{2}$ close to 1 implies a better fit design to experimental data, which is also supported with the $\mathrm{R}^{2}$ adjusted. The $\mathrm{R}^{2}$-adjusted value also explains the suitability of the design. It increases with the addition of independent variables, which are significant to a dependent variable. If the non-significant variables are added into the design, the adjusted $R^{2}$ value decreases contrary to the $R^{2}$ value that increases with the introduction of the new variables regardless of their importance. The gap between $\mathrm{R}^{2}$ and adjusted $\mathrm{R}^{2}$ should be as small as possible and not exceed 0.2 . The importance of $F$-value implies the significance of the variable in single or in interaction. The higher the $F$-value observed, the more significant the factor is. 
Table 5. The statistical analysis of the applied models.

\begin{tabular}{|c|c|c|c|}
\hline \multicolumn{4}{|c|}{ Central Composite Design } \\
\hline & CIPRO & LEVO & MOXI \\
\hline$F$ & 29.27 & 27.14 & 48.500 \\
\hline$p$ & $<0.0001$ & $<0.0001$ & $<0.0001$ \\
\hline $\mathrm{R}^{2}$ & 0.9777 & 0.9760 & 0.9842 \\
\hline $\mathrm{R}^{2}$-adjusted & 0.9443 & 0.9401 & 0.9639 \\
\hline Lack of fit & NS & NS & NS \\
\hline \multicolumn{4}{|c|}{ Doehlert Design } \\
\hline & CIPRO & LEVO & MOXI \\
\hline$F$ & 14.390 & 20.520 & 13.210 \\
\hline$p$ & 0.011 & 0.002 & 0.019 \\
\hline $\mathrm{R}^{2}$ & 0.9664 & 0.9636 & 0.9824 \\
\hline $\mathrm{R}^{2}$-adjusted & 0.8993 & 0.9262 & 0.9689 \\
\hline Lack of fit & NS & NS & NS \\
\hline \multicolumn{4}{|c|}{ Box-Behnken Design } \\
\hline & CIPRO & LEVO & MOXI \\
\hline$F$ & 2.320 & 3.430 & 4.920 \\
\hline$p$ & 0.184 & 0.054 & 0.047 \\
\hline $\mathrm{R}^{2}$ & 0.8066 & 0.8605 & 0.8986 \\
\hline $\mathrm{R}^{2}$-adjusted & 0.4854 & 0.6094 & 0.7160 \\
\hline Lack of fit & 0.006 & $<0.001$ & 0.018 \\
\hline
\end{tabular}

\subsection{The Chromatographic Analysis}

Twenty microliters of the sample was injected onto the chromatographic system. The analytes were detected with a UV detector (detection wavelength $\lambda=280 \mathrm{~nm}$ ), the temperature was ambient. The elution was isocratic. The LiChroCART column $(250 \times 4 \mathrm{~mm}, 5 \mu \mathrm{m}$, Merck, Darmstadt, Germany) with Purospher RP-18 guard column $(4 \times 4 \mathrm{~mm}, 5 \mu \mathrm{m}$, Merck, Darmstadt, Germany) were applied for chromatographic separation. The analysis for LEVO and CIPRO was done on the following mobile phase: $\mathrm{ACN}-\mathrm{MeOH}-50 \mathrm{mM} \mathrm{NaH}_{2} \mathrm{PO}_{4}-0.7 \%$ TEA $(12: 17: 35.5: 35.5 ; \mathrm{v} / \mathrm{v} / \mathrm{v} / \mathrm{v})$, the $\mathrm{pH}$ of the mobile phase was 2.5 and flow $1 \mathrm{~mL} / \mathrm{min}$. Retention time for LEVO was ca. $5.4 \mathrm{~min}$., and for CIPRO 6.2 min. The total run time did not exceed $9 \mathrm{~min}$. MOXI was analyzed on the following mobile phase which consisted of ACN-1.5\% TEA-33.8 $\mathrm{mM} \mathrm{NaH}_{2} \mathrm{PO}_{4}(27: 36.5: 36.5 ; \mathrm{v} / \mathrm{v} / \mathrm{v})$, the $\mathrm{pH}$ of the mobile phase was 2.5 and flow was $1 \mathrm{~mL} / \mathrm{min}$. The retention time for MOXI was ca. $4.8 \mathrm{~min}$., and for LEVO ca. $2.8 \mathrm{~min}$. The total time of analysis did not exceed $7 \mathrm{~min}$. The components and proportions of the constituents of the mobile phase were optimized using Box-Behnken Design. The HPLC separation was isocratic in both cases [18].

\section{Results}

\subsection{The Statistical Evaluation of the Model}

The aim of this study was to compare the suitability of the different chemometric models for the optimization of the recovery of the representatives of the fluoroquinolones. The following models were tested: BBD, CCD and DD. The design matrices are presented in Tables 1-3. The following parameters were taken into consideration: the $p$-value, the $F$-value of the ANOVA test, the coefficients of determination $\left(\mathrm{R}^{2}\right.$-value, the $\mathrm{R}^{2}$-adjusted), and lack of fit. The $p$-value should be below 0.05 . The $F$-value should take the highest values, the lack of fit should not be below 0.05 . The coefficient of variations $R^{2}$ is a measure of the amount of variation around the model, and the $R^{2}$-adjusted is adjusted for the number of terms in the model. It decreases as the number of terms in the model increases on the condition that these terms do not add value to the model. The $\mathrm{R}^{2}$ value should be higher than 0.9 and the differences between them should not exceed 0.2 [18]. 
The model which was the least suitable for estimation of the recovery was the BBD. The $p$-values for CIPRO and LEVO were not significant (Table 5). For MOXI, it was on the threshold of statistical significance. The F-values were the lowest when compared with the other models. Moreover, none of the $\mathrm{R}^{2}$ values for each analyte exceeded the value 0.9 . The $\mathrm{R}^{2}$-adjusted values were the lowest when compared with other models and the difference between them was higher than 0.2 for CIPRO and LEVO. For MOXI, it was close to this value. The lack-of-fit was significant for all analytes. That excluded the BBD model from further analysis.

The $p$-values in CCD and DD implied the significance of the models for all analytes, however, for CCD they took the lowest values (below 0.0001). The lack of fit in all cases was not significant. The coefficients of determinations $\mathrm{R}^{2}$ values exceeded 0.95 , however, it took the higher values for CCD. The lower values for $\mathrm{R}^{2}$ adjusted were noted for CIPRO and LEVO for DD. For CCD, they were higher-they exceeded the value of 0.94 , which revealed a good correlation between the independent variables. The differences between $R^{2}$ and $R^{2}$-adjusted did not exceed the value 0.2 for all analytes in CCD and DD models.

The analysis of $F$-values proved that the CCD was suitable for the optimization of the recovery of analyzed fluoroquinolones - they were the highest for CCD and they exceeded 25. For DD, they did not exceed 21, and the lowest one was noted for MOXI. For BBD, the F-value took the lowest values, which did not exceed 5 (Table 5).

The standardized Pareto Charts for recovery of the analyzed compounds for CCD are in Figure 1. The length of the bar is proportional to the standardized effect [19]. The line indicates the threshold $p=0.05$. For CIPRO and MOXI, the most significant factors are the quadratic terms of $\mathrm{pH}, \mathrm{VDCM}$ and time. For LEVO, the most significant factors are VDCM, the quadratic term of time and the VDCM $\times$ time interaction. The mutual interaction between two different independent variables for MOXI and CIPRO compounds is not as significant as for LEVO. The Pareto chart for LEVO indicates as significant all possible mutual interactions between the independent variables.
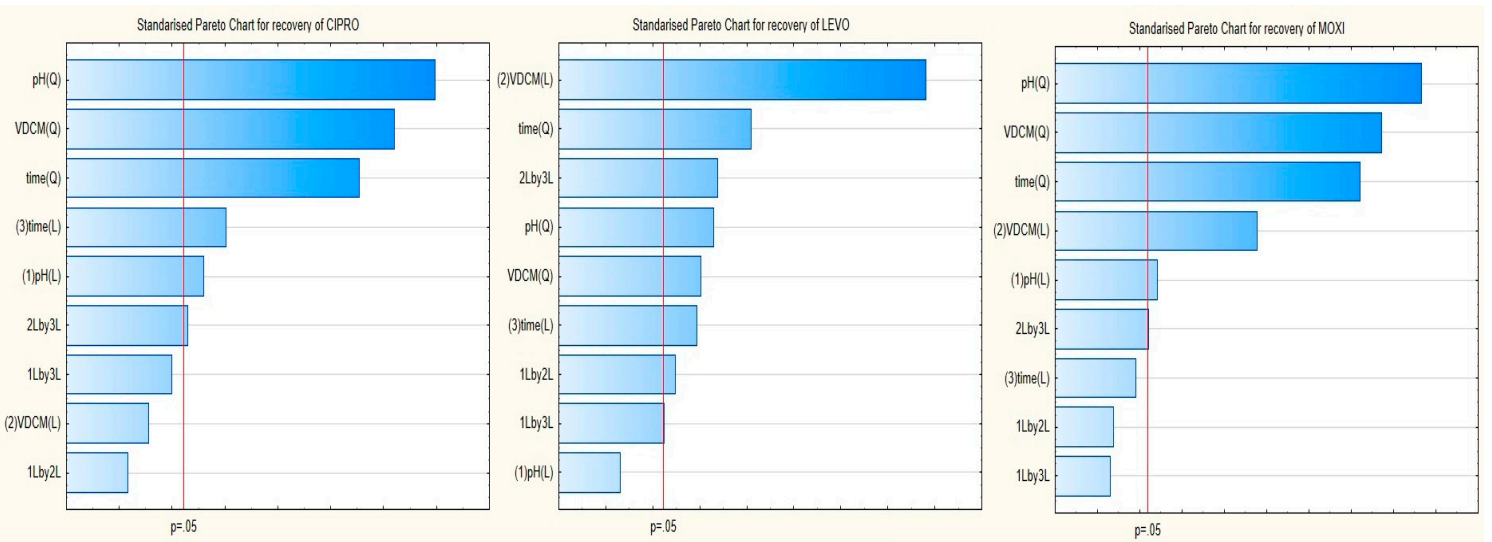

Figure 1. Standardized Pareto charts for recovery of CIPRO, LEVO and MOXI.

\subsection{Response Surface Methodology (RSM) in the Optimization of Recovery}

The statistical analysis for CIPRO and MOXI proved that $F$-values are the highest for $\mathrm{pH}^{2}, \mathrm{VDCM}^{2}$, and time ${ }^{2}$. For LEVO, the highest values are observed for VDCM, time ${ }^{2}$ and interaction VDCM $\times$ time (Table 6). The statistical analysis also proved that for LEVO all the mutual interactions between independent variables are statistically significant. 
Table 6. The statistical analysis of CCD for the analytes.

\begin{tabular}{ccccccccc}
\hline & CIPRO & \multicolumn{2}{c}{ LEVO } & \multicolumn{3}{c}{ MOXI } \\
& $\boldsymbol{F}$ & $\boldsymbol{p}$ & & $\boldsymbol{F}$ & $\boldsymbol{p}$ & & $\boldsymbol{F}$ & $\boldsymbol{p}$ \\
\hline Model & 29.27 & $<0.001$ & Model & 27.14 & $<0.001$ & Model & 48.50 & $<0.001$ \\
linear & 9.23 & 0.012 & linear & 67.11 & $<0.001$ & linear & 22.78 & 0.001 \\
$\mathrm{pH}$ & 10.10 & 0.019 & $\mathrm{pH}$ & 0.40 & 0.552 & $\mathrm{pH}$ & 8.09 & 0.025 \\
$\mathrm{~V}_{\mathrm{DCM}}$ & 1.26 & 0.305 & $\mathrm{~V}$ DCM & 185.80 & $<0.001$ & $\mathrm{~V}_{\mathrm{DCM}}$ & 57.02 & $<0.001$ \\
time & 16.23 & 0.007 & time & 15.15 & 0.008 & time & 3.23 & 0.115 \\
quadratic & 69.58 & $<0.001$ & quadratic & 18.51 & 0.002 & quadratic & 120.46 & $<0.001$ \\
$\mathrm{pH} \times \mathrm{pH}$ & 142.69 & $<0.001$ & $\mathrm{pH} \times \mathrm{pH}$ & 20.92 & 0.004 & $\mathrm{pH} \times \mathrm{pH}$ & 234.47 & $<0.001$ \\
$\mathrm{~V}_{\mathrm{DCM}} \times \mathrm{V}_{\mathrm{DCM}}$ & 108.46 & $<0.001$ & $\mathrm{~V}_{\mathrm{DCM}} \times \mathrm{V}_{\mathrm{DCM}}$ & 16.24 & 0.007 & $\mathrm{~V}_{\mathrm{DCM}} \times \mathrm{V}_{\mathrm{DCM}}$ & 180.08 & $<0.001$ \\
time $\times$ time & 82.52 & $<0.001$ & time $\times$ time & 38.08 & 0.001 & time $\times$ time & 154.15 & $<0.001$ \\
2 -FI & 3.01 & 0.116 & 2FI & 12.54 & 0.005 & 2 -FI & 2.26 & 0.168 \\
$\mathrm{pH} \times \mathrm{V}_{\mathrm{DCM}}$ & 0.11 & 0.753 & $\mathrm{pH} \times \mathrm{V}_{\mathrm{DCM}}$ & 8.79 & 0.025 & $\mathrm{pH} \times \mathrm{V}_{\mathrm{DCM}}$ & 0.59 & 0.466 \\
$\mathrm{pH} \times$ time & 4.00 & 0.092 & $\mathrm{pH} \times$ time & 6.09 & 0.049 & $\mathrm{pH} \times$ time & 0.39 & 0.555 \\
$\mathrm{VDCM} \times$ time & 6.76 & 0.041 & $\mathrm{VDCM} \times$ time & 22.74 & 0.003 & $\mathrm{VDCM} \times$ time & 5.81 & 0.047 \\
\hline
\end{tabular}

The shapes of the RSM graphs for CIPRO, LEVO and MOXI are presented in Figures 2-4.
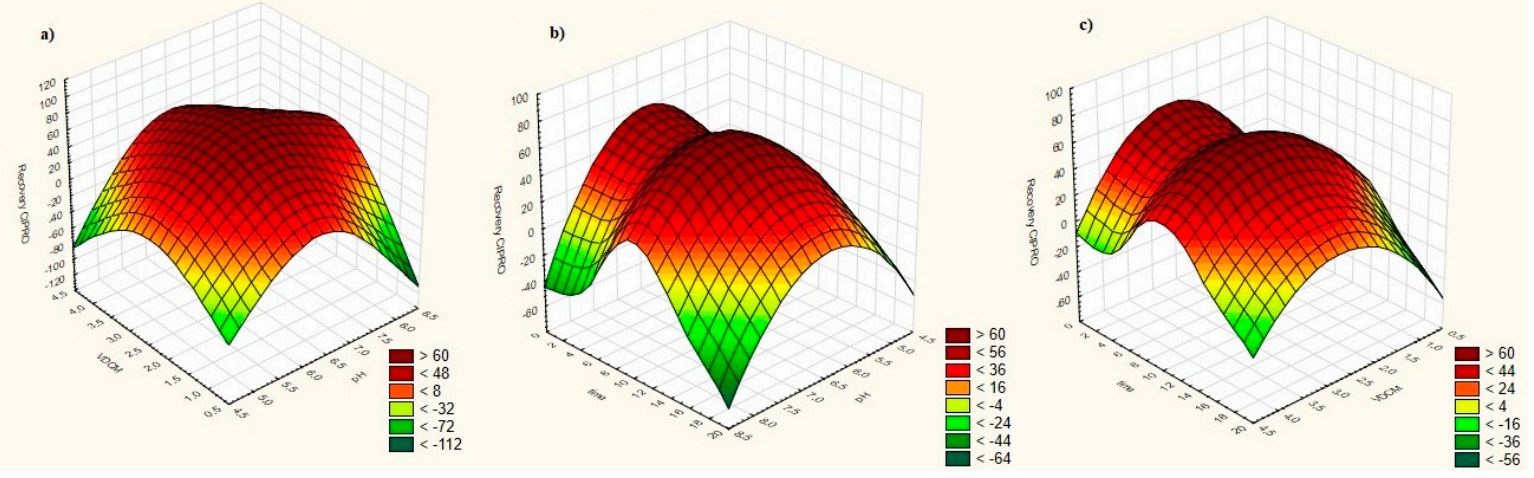

Figure 2. The RSM diagrams illustrating the change of recovery of CIPRO when analyzed: (a) VDCM and $\mathrm{pH}$; (b) time and $\mathrm{pH}$; (c) time and VDCM for CCD.
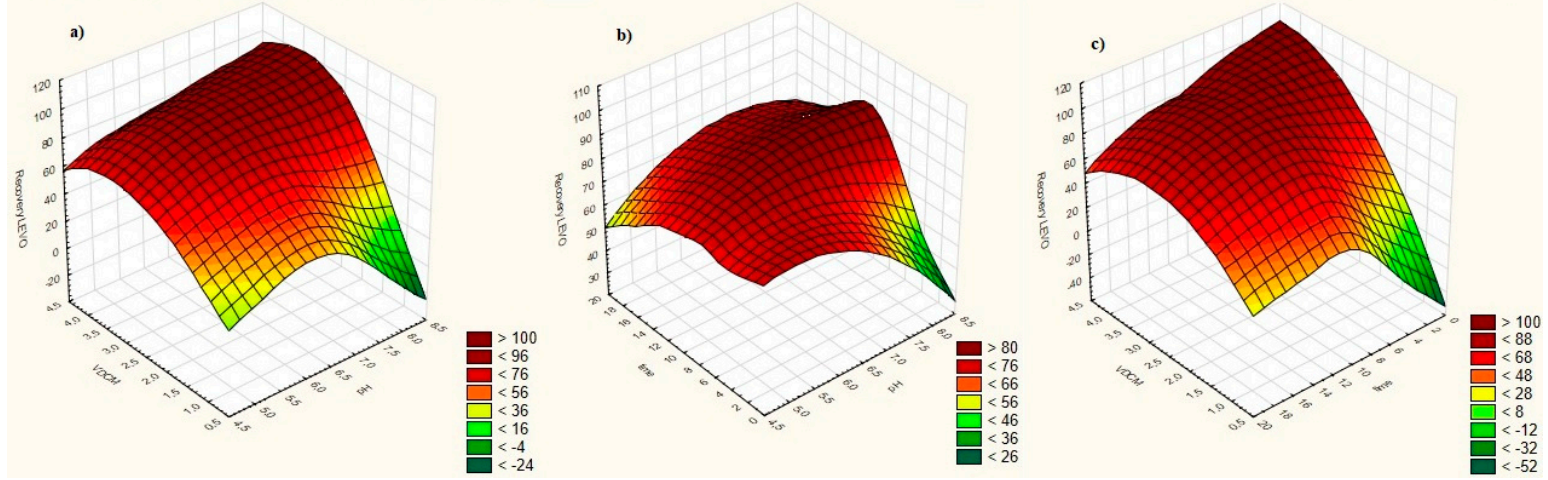

Figure 3. The RSM diagrams illustrating the change of recovery of LEVO when analyzed: (a) VDCM and $\mathrm{pH} ;(\mathbf{b})$ time and $\mathrm{pH} ;(\mathbf{c})$ time and VDCM for CCD. 

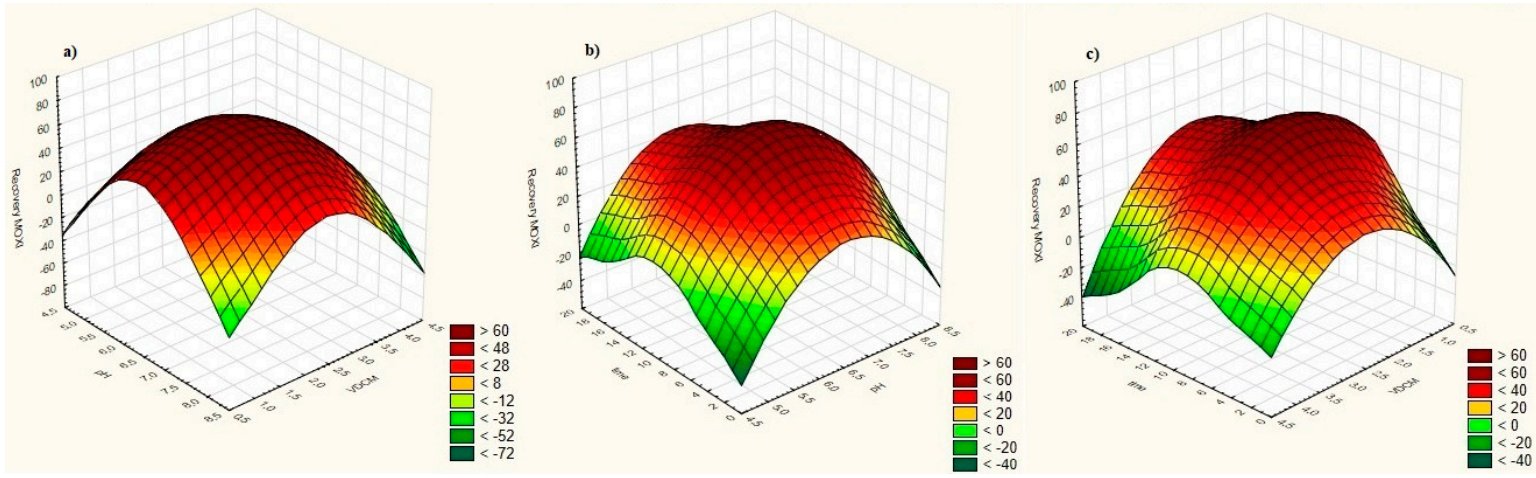

Figure 4. The RSM diagrams illustrating the change of recovery of MOXI when analyzed: (a) VDCM and $\mathrm{pH}$; (b) time and $\mathrm{pH}$; (c) time and VDCM for CCD.

The theoretical equations for each of the analytes are listed below:

$$
\begin{gathered}
\text { Recovery }_{\text {CIPRO }}=91.79+9.62 \mathrm{pH}+3.40 \mathrm{VDCM}-12.19 \text { time }-61.33 \mathrm{pH}^{2}-53.47 \mathrm{VDCM}^{2} \\
-46.64 \text { time }^{2}-2.32 \mathrm{pH} \times \mathrm{VDCM}-14.11 \mathrm{pH} \times \text { time }+18.34 \mathrm{VDCM}^{2} \text { time } \\
\text { Recovery }_{\text {LEVO }}=98.59-0.83 \mathrm{pH}+17.75 \mathrm{VDCM}+2.83 \text { time }-6.80 \mathrm{pH}^{2}-7.28 \mathrm{VDCM}^{2} \\
-9.17 \text { time }^{2}+5.11 \mathrm{pH} \times \mathrm{VDCM}+4.26 \mathrm{pH} \times \text { time }-8.22 \mathrm{VDCM}^{2} \text { time } \\
\text { Recovery }_{M O X I}=88.29+3.29 \mathrm{pH}-8.72 \mathrm{VDCM}+2.08 \text { time }-19.49 \mathrm{pH}^{2}-17.08 \mathrm{VDCM}^{2} \\
-15.80 \text { time }^{2}+1.16 \mathrm{pH} \times \mathrm{VDCM}-0.94 \mathrm{pH} \times \text { time }-3.64 \mathrm{VDCM}^{2} \times \text { time }
\end{gathered}
$$

\section{Discussion}

The analysis of the shapes of the RSM graphs for CIPRO proved that the maximum value of recovery was located inside the experimental region for all configurations ( $\mathrm{pH}$ and time vs. recovery, VDCM and time vs. recovery, and $\mathrm{pH}$ and VDCM vs. recovery). In Figure 2a, we can see that the maximum recovery observed is for $\mathrm{pH}$ 6.0-7.0 and the VDCM 2.0-3.5 mL. When $\mathrm{pH}$ is considered with the time of shaking, we can see that the maximum recovery is observed for time 8-12 min (Figure $2 b$ ). Figure $2 c$ gives an information that the maximum recovery is noted for the volume range of an extracting agent $2.0-3.5 \mathrm{~mL}$. Too high or too low $\mathrm{pH}$ reduces the recovery because of the ionization of the carboxyl group or nitrogen atom in the CIPRO molecule. The analysis of the data for CIPRO showed that the maximum recovery is observed for the intermediate values of the variables. The $\mathrm{pH}$ 6.0-7.0 combined with the VDCM 2-3 $\mathrm{mL}$ and the time of shaking 7.5-12.5 min. resulted in high recovery. The critical parameter that influences most the recovery of CIPRO is $\mathrm{pH}$. The further statistical analysis with the software indicated the following conditions for which the recovery should be the highest: 6.6 for $\mathrm{pH}, 2.5 \mathrm{~mL}$ for VDCM, and $9 \mathrm{~min}$. for the time of shaking. The predicted recovery for CIPRO estimated with equation (1) for optimal conditions should take the value $92.9 \%$. The experimental values were $92.2 \% \pm 0.8 \%, 92.4 \% \pm 1.0 \%$ and $92.9 \% \pm 1.1 \%$ for the following concentrations $2 \mathrm{mg} / \mathrm{L}, 6 \mathrm{mg} / \mathrm{L}$ and $8 \mathrm{mg} / \mathrm{L}$ respectively. The mean value for these three concentrations was $92.5 \%$. It also confirmed the suitability of the applied design.

The analysis of the RSM graph ( $\mathrm{pH}$ and VDCM vs. Recovery) showed that the maximum recovery of LEVO is observed for VDCM 3.0-4.0 mL and pH 6.0-7.0 (Figure 3a). The major restricting agent of LEVO recovery is the VDCM. It decreases with the decrease in the volume of the extracting solvent. However, the higher volumes of the extracting agent also reduces the recovery. It was also noted by Asadollahzadeh et al. [19], who investigated the impact of an extracting agent on the microextraction of arsenic compounds, that the enrichment factor decreases with the increase of the extracting agent. The impact of the time is illustrated in Figure 3b,c. It indicated that the region with the maximum recovery is observed for the time of shaking 7.5-14.0 min, $\mathrm{pH}$ from 6.0 to 7.0, and VDCM 3.0-4.0 mL. 
When the time of shaking shortens, and the applied VDCM is $2.0 \mathrm{~mL}$ and lower, the recovery decreases especially for the higher $\mathrm{pH}$ levels. The impact of $\mathrm{pH}$ on the recovery is significant for low VDCM. In all graphs, the maximum is located inside the investigated region. The VDCM and pH vs. Recovery, and $\mathrm{pH}$ and time vs. Recovery graphs indicate that variation of the $\mathrm{pH}$ level impacts the recovery significantly for higher values of $\mathrm{pH}$ when considered with low VDCM and short time of shaking. The software analysis indicated that the most optimal conditions for recovery are $\mathrm{pH}$ 6.4, VDCM $3.5 \mathrm{~mL}$ and time of shaking $13 \mathrm{~min}$. The expected value for LEVO recovery calculated with equation (2) was $101.6 \%$. The observed value for the concentration $2 \mathrm{mg} / \mathrm{L}$ was $99.9 \% \pm 0.2 \%$, and for concentrations $6 \mathrm{mg} / \mathrm{L}$ and $8 \mathrm{mg} / \mathrm{L}$ was $100 \% \pm 0.1 \%$. The mean value for these concentrations was $100 \%$.

The highest recovery for MOXI is observed for $\mathrm{pH}$ 6.0-7.0 and the VDCM 2-3 mL (Figure 4a). According to the graph in Figure $4 \mathrm{~b}$, the highest recovery is noted for $\mathrm{pH}$ 6.0-7.0 and time of shaking 10-12 min. In Figure 4a,c, the maximum of the recovery is stretched to low values of DCM, which suggests the theoretical possibility of the use of relatively small amounts (less than $3 \mathrm{~mL}$ ) of the organic solvent at the intermediate values of $\mathrm{pH}$ (Figure 4a). The most optimal conditions for MOXI recovery are the following: $\mathrm{pH}$ 6.6, $2.3 \mathrm{~mL}$ for VDCM and $10 \mathrm{~min}$ for the time of shaking. The predicted value of MOXI recovery with Equation (3) is 89.5\%. The observed values were $90.5 \% \pm 1.1 \%, 90.9 \% \pm 0.9 \%$ and $92.2 \% \pm 0.7 \%$ for the following concentrations: $2 \mathrm{mg} / \mathrm{L}, 6 \mathrm{mg} / \mathrm{L}$ and $8 \mathrm{mg} / \mathrm{L}$ respectively. The observed mean value for these concentrations is $91.2 \%$. The shapes of the response plots indicated for all analytes that the maximum recovery is located inside the experimental region.

\section{Conclusions}

According to the literature data, BBD, DD and CCD can be applied in the analysis of the extraction step for different compounds [20]. This study gives an answer to which of the investigated model is suitable for the analysis of the fluorquinolones' recovery from plasma. The statistical analysis excluded BBD. For DD, the F-values indicated that this design is better than BBD. However, the detailed statistical analysis proved that in the optimization fluoroquinolones, the most suitable is CCD; the highest values for the ANOVA test were noted for CCD. Szerkus et al. also used the CCD in the extraction of levofloxacin - it was an extraction with methanol from prostatic tissue [21]. Ferreira et al. indicated that DD for the $\mathrm{k}=3$ is the same as BBD [20]. The suitability of the chosen model was confirmed by the measurements-the predicted values of recovery were similar to the calculated ones.

The statistical analysis proved that the $\mathrm{pH}$ is the factor that limits the recovery of CIPRO and MOXI. In the case of LEVO, the factor that most influences the recovery is the VDCM.

The conducted statistical analysis not only indicated the most relevant factors that influence the recovery of the analytes but also makes it possible to reduce the use of the reagents. It is a very important issue from both the economic and ecological point of view.

Author Contributions: A.C.- conceived and designed the experiments, analysed the data, contributed the reagents, materials, analysis tools and wrote the paper; A.C. and H.J. prepared the samples for HPLC analysis and did the measurements. All authors have read and agreed to the published version of the manuscript.

Funding: This research received no external funding

Conflicts of Interest: The authors declare no conflict of interest

\section{References}

1. Czyrski, A.; Kondys, K.; Szałek, E.; Karbownik, A.; Grześkowiak, E. The pharmacokinetic interaction between levofloxacin and sunitinib. Pharmacol. Rep. 2015, 67, 542-544. [CrossRef] [PubMed]

2. Czyrski, A.; Anusiak, K.; Teżyk, A. The degradation of levofloxacin in infusions exposed to daylight with an identification of a degradation product with HPLC-MS. Sci. Rep. 2019, 9, 3621. [CrossRef] [PubMed] 
3. Czyrski, A. Analytical Methods for Determining Third and Fourth Generation Fluoroquinolones: A Review. Chromatographia 2017, 80, 181-200. [CrossRef] [PubMed]

4. Baranda, A.B.; Etxebarria, N.; Jiménez, R.M.; Alonso, R.M. Development of a liquid-liquid extraction procedure for five 1,4-dihydropyridines calcium channel antagonists from human plasma using experimental design. Talanta 2005, 67, 933-941. [CrossRef] [PubMed]

5. Bioanalytical Method Validation Guidance for Industry; 2018; pp. 1-44. Available online: https://www. fda.gov/files/drugs/published/Bioanalytical-Method-Validation-Guidance-for-Industry.pdf (accessed on 3 March 2020).

6. Hibbert, D.B. Experimental design in chromatography: A tutorial review. J. Chromatogr. B Analyt. Technol. Biomed. Life Sci. 2012, 910, 2-13. [CrossRef] [PubMed]

7. Sahu, P.K.; Ramisetti, N.R.; Cecchi, T.; Swain, S.; Patro, C.S.; Panda, J. An overview of experimental designs in HPLC method development and validation. J. Pharm. Biomed. Anal. 2018, 147, 590-611. [CrossRef] [PubMed]

8. Bezerra, M.A.; Santelli, R.E.; Oliveira, E.P.; Villar, L.S.; Escaleira, L.A. Response surface methodology (RSM) as a tool for optimization in analytical chemistry. Talanta 2008, 76, 965-977. [CrossRef] [PubMed]

9. Dejaegher, B.; Heyden, Y.V. Experimental designs and their recent advances in set-up, data interpretation, and analytical applications. J. Pharm. Biomed. Anal. 2011, 56, 141-158. [CrossRef] [PubMed]

10. Khodadoust, S.; Sadeghi, H.; Pebdani, A.A.; Mohammadi, J.; Salehi, A. Optimization of ultrasound-assisted extraction of colchicine compound from Colchicum haussknechtii by using response surface methodology. J. Saudi Soc. Agric. Sci. 2017, 16, 163-170. [CrossRef]

11. Ares, A.M.; Fernández, P.; Regenjo, M.; Fernández, A.M.; Carro, A.M.; Lorenzo, R.A. A fast bioanalytical method based on microextraction by packed sorbent and UPLC-MS/MS for determining new psychoactive substances in oral fluid. Talanta 2017, 174, 454-461. [CrossRef] [PubMed]

12. Tran, Q.T.; Vu Thi, T.L.; Do, T.L.; Pham Thi, H.M.; Hoang Thi, B.; Chu, Q.T.; Lai Phuong, P.T.; Do, H.N.; Hoang Than, H.T.; Ta Thi, T.T.; et al. Optimization of Microwave-Assisted Extraction Process of Callicarpa candicans (Burm. f.) Hochr Essential Oil and Its Inhibitory Properties against Some Bacteria and Cancer Cell Lines. Processes 2020, 8, 173. [CrossRef]

13. Gao, M.; Wang, H.; Ma, M.; Zhang, Y.; Yin, X.; Dahlgren, R.A.; Du, D.; Wang, X. Optimization of a phase separation based magnetic-stirring salt-induced liquid-liquid microextraction method for determination of fluoroquinolones in food. Food Chem. 2015, 175, 181-188. [CrossRef] [PubMed]

14. Athankar, K.K.; Wasewar, K.L.; Varma, M.N.; Shende, D.Z. Reactive extraction of gallic acid with tri-n-caprylylamine. New J. Chem. 2016, 40, 2413-2417. [CrossRef]

15. Bezerra, M.A.; Bruns, R.E.; Ferreira, S.L.C. Statistical design-principal component analysis optimization of a multiple response procedure using cloud point extraction and simultaneous determination of metals by ICP OES. Anal. Chim. Acta 2006, 580, 251-257. [CrossRef] [PubMed]

16. Durán Guerrero, E.; Natera Marín, R.; Castro Mejías, R.; García Barroso, C. Optimisation of stir bar sorptive extraction applied to the determination of volatile compounds in vinegars. J. Chromatogr. A 2006, 1104, 47-53. [CrossRef] [PubMed]

17. Ebrahimzadeh, H.; Asgharinezhad, A.A.; Adlnasab, L.; Shekari, N. Optimization of ion-pair based hollow fiber liquid phase microextraction combined with HPLC-UV for the determination of methimazole in biological samples and animal feed. J. Sep. Sci. 2012, 35, 2040-2047. [CrossRef] [PubMed]

18. Czyrski, A.; Sznura, J. The application of Box-Behnken-Design in the optimization of HPLC separation of fluoroquinolones. Sci. Rep. 2019, 9, 19458. [CrossRef] [PubMed]

19. Asadollahzadeh, M.; Tavakoli, H.; Torab-Mostaedi, M.; Hosseini, G.; Hemmati, A. Response surface methodology based on central composite design as a chemometric tool for optimization of dispersive-solidification liquid-liquid microextraction for speciation of inorganic arsenic in environmental water samples. Talanta 2014, 123, 25-31. [CrossRef] [PubMed] 
20. Ferreira, S.L.C.; Bruns, R.E.; da Silva, E.G.P.; Dos Santos, W.N.L.; Quintella, C.M.; David, J.M.; de Andrade, J.B.; Breitkreitz, M.C.; Jardim, I.C.S.F.; Neto, B.B. Statistical designs and response surface techniques for the optimization of chromatographic systems. J. Chromatogr. A 2007, 1158, 2-14. [CrossRef] [PubMed]

21. Szerkus, O.; Jacyna, J.; Wiczling, P.; Gibas, A.; Sieczkowski, M.; Siluk, D.; Matuszewski, M.; Kaliszan, R.; Markuszewski, M.J. Ultra-high performance liquid chromatographic determination of levofloxacin in human plasma and prostate tissue with use of experimental design optimization procedures. J. Chromatogr. B Anal. Technol. Biomed. Life Sci. 2016, 1029-1030, 48-59. [CrossRef] [PubMed]

(C) 2020 by the authors. Licensee MDPI, Basel, Switzerland. This article is an open access article distributed under the terms and conditions of the Creative Commons Attribution (CC BY) license (http://creativecommons.org/licenses/by/4.0/). 